bei dem der von der Anfrage betroffene Kollege während seines Studiums in München 1961/62 Staatsrecht hörte.

Prof. Maunz war damals gleichzeitig bayrischer Kultusminister. Neben seinem Kommentar zum Bonner Grundgesetz hat Prof. Maunz u. a. auch ein Buch über „Gestalt und Recht der Polizei« geschrieben. In diesem 1943 erschienenen Buch finden sich zur Bindung von Staatsbediensteten an das Gesetz u. a. folgende Ausführungen:

"Aus verständlichen Gründen wandte sıch die neue Polizei nach der Machtergreifung gegen das Einfangen ihrer Tätıgkeit in Normen, das unter dem Blickpunkt der geschıchtlichen Ereignisse als liberal erscheinen mußte und das die Durchschlagskraft des polizıelichen Wirkens hemmte. *

(Maunz a. a. O., S. 9)

"Zweck und Arbeitsumfang der Geheimen Staatspolizei nach dem heute erreichten Stand können in keiner Weise durch die gesetzlichen Bestimmungen erschöpft werden, die für sie erlassen worden sind. Das ist wohl letzten Endes der Grund dafür, daß eıne Reihe von geltenden Vorschriften nıcht mehr veröffentlicht worden ist. Zu ihnen gehören die Vorschriften über die polizeiliche Schutzhaft. Bekannt ist die rechtliche Ausgangsstellung für das Wirken der Geheimen Staatspolizei, es ist die Verordnung zum Schutze von Volk und Staat vom 28.2.33, die durch Aufhebung des die Unverletzlichkeit der Freiheit der Person verbürgenden Verfassungsartikels Schranken des früheren Rechtssystems wegräumte."

(Maunz a.a. O., S. 49)

Die Fachbereichskonferenz fragt den Abg. Borsche:

Hält er es für angebracht, daß ein Parteifreund in einem Land der Bundesrepublik Deutschland Kultusminister werden kann, der - wie die Leseproben erkennen lassen - offensichtlich unter Mißachtung jeder freiheitlich demokratischen Grundordnung die Konzentrationslager juristisch absegnete?

Wenn nein: Hat er Konsequenzen aus diesem Vorgang gezogen? Welche?

\title{
Symposium über die Genese von Kriminalitätsnormen
}

Der Arbeitskreis Junger Kriminologen veranstaltet vom 6.3. (abends) bis 9. 3. 1975 (mittags) im Zentrum für interdisziplinäre Forschung, Bielefeld, ein Symposium über die Setzung von Kriminalitätsnormen (Vorbereitung: Rüdiger Lautmann, Hans Haferkamp, Fritz Sack).

Die Vorschriften des StGB, des Nebenstrafrechts, der Prozeßordnungen u. a. bilden einen Teil der institutionellen Rahmenbedingungen im Prozeß der sozialen Kontrolle, insbesondere in der Kriminalisierung. Nach früher herrschender und noch heute viel vertretener Meinung wurden diese Normen als traglos gegeben hingenommen; der Prozeł ihrer Entstehung blieb unanalysiert. Das Defizit an kriminologischer Theorie auf diesem Teilgebiet ist dementsprechend beträchtlich.

Es wird vorgeschlagen, auf dem Symposium eine Bestandsaufnahme der vorliegenden Forschungsergebnisse, der offenen Fragen sowie der laufenden und geplanten Projekte zu erarbeiten. Dabei könnten beispielsweise diese Einzelprobleme angesprochen werden:

- Ablauf und Aushandlung von Normsetzung auf ministerieller und parlamentarischer Ebene; 
- politische Konstellationen, bei denen die politischen Parteien in Richtung auf eine Änderung des Normenbestandes aktiv werden;

- Einflüsse der Instanzen sozialer Kontrolle auf die Normsetzung;

- Einflüsse außerverfassungsmäßiger Instanzen auf die Normsetzung;

- Funktionalität bestimmter Normen für Interessen- und Machtgruppen; obne daß diese selbst unmittelbar in die Normsetzung eingegriffen haben;

- gesellschaftliche Interessen und Gruppen, die es nicht vermögen, sich im Normsetzungsprozeß zu artikulieren;

- Unterlassung von Kriminalisierung und Entkriminalisierung durch non-deciding;

- Strafrecht als Surrogat für einen ökonomischen Schadensausgleich zwischen Opfer und Täter;

- Umsetzung herrschender Moralnormen in (dann in der Regel) opferlose Verbrechenstatbestände;

- Prozesse der Entkriminalisierung;

- Möglichkeiten der Einflußnahme von Rechts- und Sozialwissenschaftlern auf die Normsetzung.

Um über einen so weitgespannten und bislang wenig strukturierten Themenbereich fruchtbar diskutieren zu können, wird von jedem Teilnehmer verbindlich erwartet, daß er vorher ein Papier (von 4 bis maxımal 10 Seiten) anfertigt, in dem er entweder seine Position zu einigen der in dieser Ankündigung genannten Probleme umreißt oder über ein laufendes einschlägiges Projekt berichtet. Diese Papiere werden an alle Teilnehmer versandt.

Anmeldungen werden nur bei Vorlage eines Positions- oder Projektpapiers bis zum 1. 2. 1975 entgegengenommen. Adresse des Koordinators: Rüdiger Lautmann, 28 Bremen 33, Achterstraße - Universität. Die Einladung durch das ZiF und der Versand der vervielfältigten Papiere finden ab IO. 2. 1975 statt.

Arbeitskreis Junger Krimmologen 